\title{
IMPLEMENTASI ITEM BASED COLLABORATIVE FILTERING DALAM PEMBERIAN REKOMENDASI AGENDA WISATA BERBASIS ANDROID
}

\author{
Yudi Setiawan ${ }^{1}$, Angga Nurwanto ${ }^{2}$, Aan Erlansari $^{3}$ \\ (telp: 0736-341022; fax: 0736-341022) \\ ${ }^{1}$ ysetiawaneunib.ac.id \\ 2angganurwanto01@gmail.com \\ 3 aanerlansari@unib.ac.id
}

${ }^{1,2,3}$ Program Studi Informatika, Fakultas Teknik, Universitas Bengkulu J1. WR. Supratman Kandang Limun Bengkulu 38371A, Kota Bengkulu

\begin{abstract}
Abstrak: Terbatasnya pengetahuan seseorang tentang daerah yang dituju, menjadi kendala tersendiri bagi para pelancong ataupun para eksekutif yang sedang melakukan perjalanannya ke suatu daerah dengan demikian perlu adanya pemandu yang bisa menuntun dan menunjukkan posisi dimana saat ini seseorang itu berada. Penelitian ini membangun sebuah Aplikasi Android yang mampu merekomendasikan pariwisata yang ada di Kota Bengkulu berbasis Android. Penelitian ini menggunakan metode item based collaborative filtering dimana sistem merekomendasikan pariwisata berdasarkan itemitem yang disukai oleh user. Metode ini bertujuan memprediksi item tertentu untuk seorang pengguna berdasarkan preferensi pengguna sebelumnya dan opini dari pengguna lain yang mirip. Penelitian ini menghasilkan sistem informasi rekomendasi Pariwisata Bengkulu berbasis Android yang di uji menggunakan metode pengujian blackbox dengan hasil $100 \%$ berhasil dan memperoleh nilai user experience sangat baik yaitu sebesar $90,752 \%$ pada pengujian usability testing.

Kata Kunci: Agenda Pariwisata, Sistem Rekomendasi, Item Based Collaborative Filtering, Android.
\end{abstract}

\begin{abstract}
The limited knowledge of someone about the destination area becomes a separate consideration for executives who are traveling to an area so there needs to be a guide who can guide and determine the position where there is currently a need. This research builds an Android Application using Java code that is able to recommend tourism in the City of Bengkulu based on Android. This study uses the item based collaborative filtering method where the system recommends tourism based on items that are liked by the user. This method aims to predict certain items for a user based on previous user preferences and opinions from other similar users. This research resulted in an Android-based Bengkulu Tourism recommendation information system that was tested using the black-box testing method with $100 \%$ results succeeding and obtaining very good user experience values, which amounted to $90.752 \%$ in usability testing Keywords: Recommended Tourism, Item Based Collaborative Filtering, Java, Android.
\end{abstract}

\section{PENDAhUluan}

Rencana besar pemerintah Provinsi Bengkulu untuk menjadikan daerah ini menjadi destinasi kunjungan Internasional melalui program tahun kunjungan wisata internasional Visit Bengkulu tahun 2020 mendatang rupanya tidak main-main. Berbagai langkah sudah dipersiapkan Pemprov Bengkulu. Setidaknya ada 7 event pariwisata yang akan kita gelar, kegiatan tersebut lebih menfokuskan pada event-event yang mengeksposkan wisata alam, kuliner, serta seni budaya Provinsi Bengkulu, yang akan berasal dari seluruh Kabupaten dan Kota se-Provinsi Bengkulu, yang mana puncaknya nanti pada tahun 2020, saat ulang tahun Provinsi Bengkulu yang ke- 
Jurnal Pseudocode, Volume VI Nomor 1, Februari 2019, ISSN 2355-5920, e-ISSN 2655-1845 www.ejournal.unib.ac.id/index.php/pseudocode

52, yang disertai dengan 52 event festival Wonderful Bengkulu,"kata Wakil Gubernur Bengkulu Rohidin Mersyah, saat usai menghadiri seminar bertajuk Pengembangan Potensi Pariwisata menuju Visit Bengkulu 2020, di salah satu hotel Kota Bengkulu [1].

Agenda pariwisata merupakan catatan perjalanan pariwisata yang akan dikunjungi atau yang telah dikunjungi untuk tujuan tertentu. Tujuan dari para wisatawan adalah menggunakan atau memanfaatkan waktu senggang, baik rekreasi (berlibur), keperluan kesehatan, pelajaran dan pengetahuan, serta untuk menjalankan ibadah maupun olahraga untuk keperluan usaha atau bisnis, kunjungan keluarga, menjalankan tugas tugas, serta menghadiri konferensi. Terbatasnya pengetahuan seseorang tentang daerah yang dituju, menjadi kendala tersendiri bagi para pelancong ataupun para eksekutif yang sedang melakukan perjalanannya ke suatu daerah dengan demikian perlu adanya pemandu yang bisa menuntun dan menunjukkan posisi dimana saat ini seseorang itu berada [2].

Jika hanya mengandalkan situs yang ada pada Pemerintahan Provinsi Bengkulu sangatlah sederhana di situs tersebut tidak memberikan informasi secara lengkap pariwisata dan tidak bisa memberikan rekomendasi pariwisata. Sehingga wisatawan tidak mendapatkan rekomendasi tempat pariwisata yang akan dikunjungi [3].

Item Based Collaborative Filtering, metode ini menggunakan rekomendasi kepada user dihitung dengan menentukan item yang mirip dengan item lain yang disukai oleh pelanggan tersebut. Pada metode ini hubungan atara item-item lebih statis, sehingga membutuhkan perhitungan yang lebih sedikit tetapi mempunyai kualitas yang sama dibandingkan dengan metode user-based [4].
Menerapkan sistem rekomendasi dalam menarik para wisatawan berkunjung, dilakukan dengan sistem memberikan rekomendasi mengenai objek pariwisata yang diinginkan. Wisatawan dapat menentukan objek pariwisata berdasarkan informasi tentang objek wisata. Selain itu, wisatawan dapat menyusun agenda tujuan wisata yang ingin didatangi jika objek pariwisata tersebut memiliki lebih dari satu jenis objek wisata, ataupun objek wisata tersebut berdekatan dengan objek wisata lainnya. Sehingga sistem rekomendasi dapat memberikan rekomendasi tujuan wisata berdasarkan profil objek wisata dan agenda yang diinginkan oleh wisatawan [5].

\section{LANDASAN TEORI}

\section{A. Sistem Rekomendasi}

Menurut Sebastia, L et al dalam [6] sistem rekomendasi merupakan sebuah alat personalisasi yang menyediakan pengguna sebuah informasi daftar item-item yang sesuai dengan keinginan masing-masing pengguna. Sistem rekomendasi menyimpulkan preferensi pengguna dengan menganalisa ketersediaan data pengguna, informasi tentang pengguna dan lingkungannya. Oleh karena itu Sebastia, L et al menyatakan sistem rekomendasi akan menawarkan kemungkinan dari penyaringan informasi personal sehingga hanya informasi yang sesuai dengan kebutuhan dan preferensi pengguna yang akan ditampilkan di sistem dengan menggunakan sebuah teknik atau model rekomendasi.

Sistem Rekomendasi dibangun unutuk memudahkan para pengguna, hal ini berdasarkan Penelitian Sistem Rekomendasi Kuliner Bengkulu yang menghasilkan kemudahan dan efisiensi dalam pemberian rekomendasi sebesar $79 \%$. Evaluasi dari Sistem Rekomendasi Kuliner 
Jurnal Pseudocode, Volume V Nomor 2, September 2018, ISSN 2355-5920, e-ISSN 2655-1845 www.ejournal.unib.ac.id/index.php/pseudocode

Bengkulu dapat meningkatkan pengalaman tersebut. Untuk membuat sistem rekomendasi pengguna dalam pemilihan wisata kuliner [7]. menggunakan metode item-based ada dua langkah yang harus dilakukan, yaitu seperti berikut [9].

\section{B. Agenda}

Berikut ini adalah Arti, Makna, Pengertian, Definisi dari kata "agenda" menurut kamus besar bahasa Indonesia (KBBI) dan menurut para ahli bahasa. Arti kata agenda-agen-da/ agénda/ n 1 . buku catatan yg bertanggal untuk satu tahun: acara rapat itu telah dicatat dl --;2.acara (yg akan dibicarakan dl rapat): hal itu tercantum juga dl -rapat; --politik tema yg akan dibicarakan dl rapat politik: perebutan kursi DPR dan jabatan dl pemerintahan sudah tidak akan ada lagi dl -politik di masa datang; meng-a-gen-da-kan $\mathrm{v}$ memasukkan dl acara (rapat, seminar) [8].

\section{Metode Penelitian}

A. Sistem Rekomendasi dan Collaborative Filtering

Sistem rekomendasi adalah program perantara atau perwakilan yang secara cerdas menyusun daftar dari informasi yang diperlukan dan mencocokkan berdasarkan keinginan dari pengguna. Salah satu cara yang digunakan untuk menentukan sistem rekomendasi terhadap item/produk adalah collaborative filtering.

Collaborative filtering adalah teknik yang paling banyak digunakan pada sistem rekomendasi dengan cara menjumlahkan rating atau pilihan dari suatu produk, menemukan profil pengguna dengan melihat history rating yang diberikan pengguna, dan menghasilkan suatu rekomendasi baru berdasarkan perbandingan antar pola pengguna, nilai rating berupa binary (suka/tidak suka) atau voting. Pada algoritme item-based akan menghitung kesamaan di antara item, dilihat dari rating yang diberikan pengguna untuk item

\section{i) Menghitung Similarity}

Menghitung kemiripan antara satu item dengan item lainnya. Rumus yang biasa dipakai adalah Cosine Simility Measures, yang menghitung kemiripan antara dua item dari sudut kosinus yang tersebuat identik. Sedangkan jika nilainya 0 , maka dua item tersebut sama sekali tidak mempunyai kemiripan.

$\operatorname{sim}(i, j)=\frac{\sum u \epsilon U(r u, i-r u)(r u, j-r u)}{\sqrt{\sum u \epsilon U(r u, i-r u)^{2}} \sqrt{(r u, j-r u)^{2}}}$

Keterangan :

$\operatorname{sim}(i, j)=$ nilai kemiripan antara pariwisata $i$ dan pariwisata $j$,

$\Sigma u \epsilon U=$ himpunan user $\mathrm{u}$ yang memberikan rate pada pariwisata $i$ dan pariwisata $j$,

$r u, i=$ rating $u$ ser $u$ pada produk $i$,

$r u, j \quad=$ rating $u$ ser $u$ pada produk $j$,

ru = rata-rata rating user $u$

Jika kemiripan sudah dihitung, maka kita akan mengurutkan item-item berdasakan similarity, item-item yang mempunyai simility besar akan berada pada urutan atas, dan sebalikanya. Hasil dari algoritme ini $-1 \mathrm{~s} / \mathrm{d} 1$. Jika nilai similarity antara kedua item mendekati +1 , maka kedua item akan semakin mirip satu sama lain. Sebaliknya, jika mendekati -1, maka kedua item itu akan semakin bertolak belakang. Jika 0, maka tidak mirip sama sekali [8].

ii) Menghitung prediksi rating

Menghitung prediksi rating dari item-item tersebut dengan membandikan rating yang pernah diberikan pengguna pada suatu item dengan kemiripan antara item tersebut dengan item 
Jurnal Pseudocode, Volume VI Nomor 1, Februari 2019, ISSN 2355-5920, e-ISSN 2655-1845 www.ejournal.unib.ac.id/index.php/pseudocode

lainnya. Metode yang digunakan merupakan metode Weighted Sum.

$$
P(u, j)=\frac{\sum i \epsilon I(R u, i * S i, j)}{\sum i \epsilon I|S i, j|}
$$

Keterangan:

$P(u, j)=$ prediksi untuk $u$ ser $u$ pada pariwisata $j$

i $\mathrm{I}=$ himpunan pariwisata yang mirip dengan pariwisata $j$

$R u, I=$ rate user $u$ pada pariwisata $i$

$S i, j=$ nilai kemiripan antara pariwisata $i$ dan pariwisata $j$

Jika prediksi rating sudah dihitung, maka rekomendasi item pun dapat dihasilkan.

\section{ANALISA DAN DISKUSI}

\section{A. Analisis Sistem}

Analisa sistem adalah suatu proses analisa beberapa bagian sistem yang akan dibangun. Analisa itu meliputi analisis fungsional dan pemahaman alur kerja data. Sistem yang akan dibangun nantinya akan menggunakan bahasa pemrograman java dan database Firebased.

\section{B. Analisis Alur Kerja Data}

Alur kerja data dari item based collaborative filtering untuk rekomendasi pariwisata kota bengkulu terbagi ke dalam beberapa tahap yang dimulai dari komponen mulai hingga komponen selesai. Alur kerja data pada sistem rekomendasi agenda wisata ditunjukkan pada Gambar 1 Flowchart Sistem Rekomendasi Dengan Mengimplementasikan Collaborative Filtering.

\section{Usecase Diagram}

Adapun aktor yang terlibat dalam menggunakan sistem rekomendasi agenda pariwisata adalah Admin dan Pengguna/ Pengunjung dari sistem rekomendasi agenda pariwisata ini. Aktivitas yang dapat dilakukan oleh
Use Case diagram.

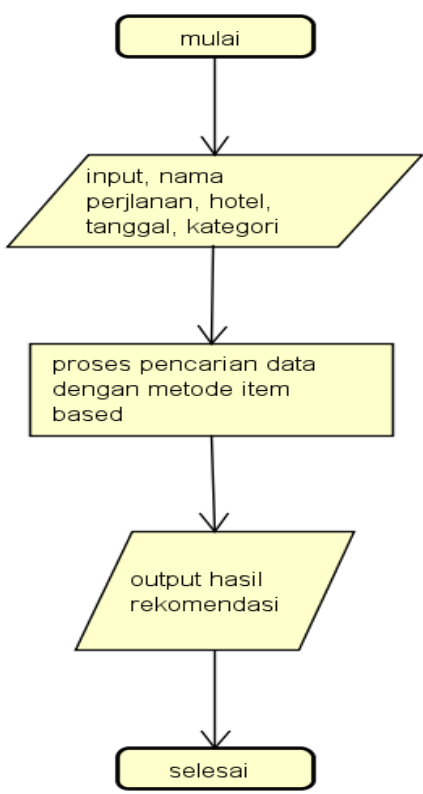

Gambar 1. Flowchart Sistem Rekomendasi Dengan Mengimplementasikan Collaborative Filtering

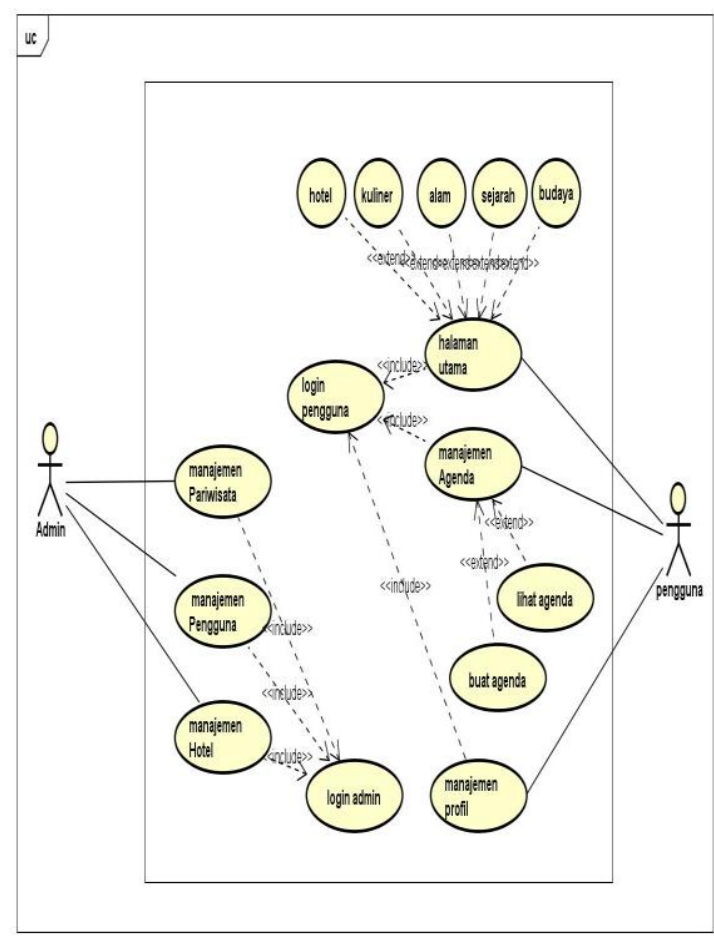

Gambar 2. Use Case Diagram Sistem Rekomendasi Agenda Wisata Dengan Menggunakan Collaborative Filtering 
Jurnal Pseudocode, Volume V Nomor 2, September 2018, ISSN 2355-5920, e-ISSN 2655-1845 www.ejournal.unib.ac.id/index.php/pseudocode

\section{HASIL DAN PEMBAHASAN}

\section{A. Implementasi Antar Muka}

Antar muka dari sistem rekomendasi agenda pariwisata dengan metode Collaborative Filtering, yang meliputi antar muka untuk penguna/ pengunjung dan admin pengelola.

i) Halaman Utama Pengunjung

Tampilan halaman utama dapat dilihat pada Gambar 3. Pada halaman ini terdapat rekomendasi dengan menggunakan metode user-based collaborative filtering berupa menu pencarian populer dan menu pencarian terpopuler.

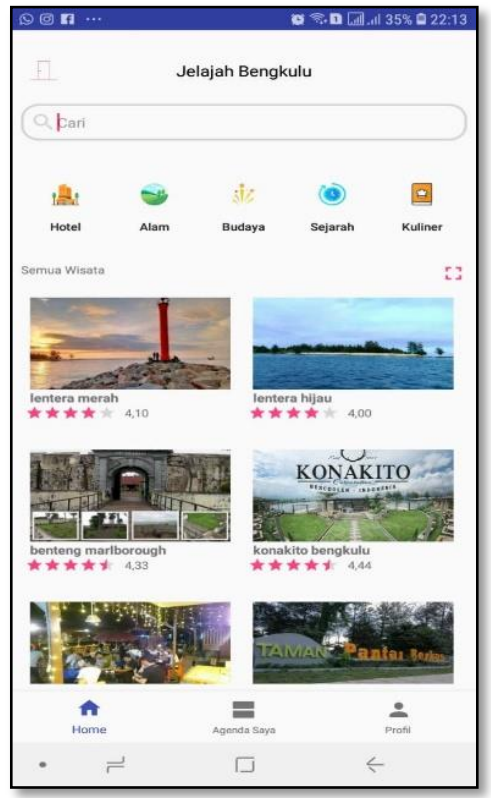

Gambar 3. Antar Muka Home Page

ii) Halaman Detail Pariwisata

Pada halaman detail pariwisata user dapat melihat info detail pariwisata dari gambar pariwisata, info atau deskripsi dari pariwisata tersebut, bias mengecek lokasi atau rute wisata dengan mengakses maps, dan dapat memberikan rating serta ulasan pada tempat wisata tersebut.

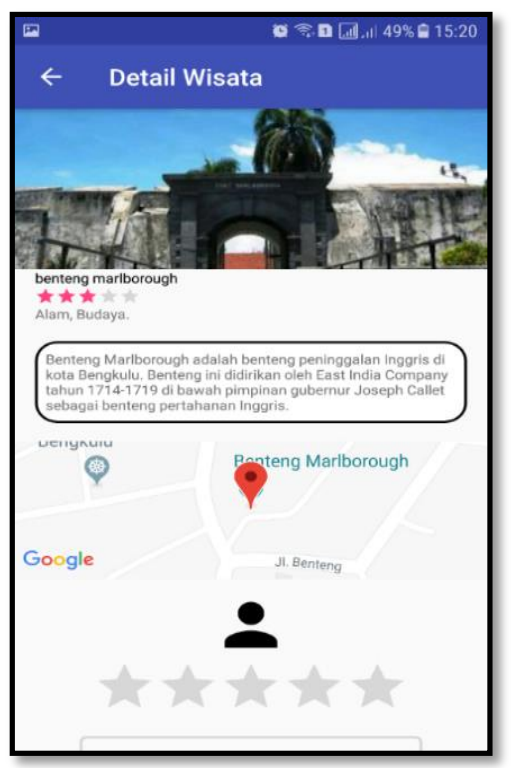

Gambar 4. Antar Muka Detail Objek Pariwisata

iii) Halaman Pembuatan Agenda

Pada halaman Agenda saya terdapat beberapa perintah yang harus diisi user apabila ingin mendapatkan sebuah rekomendasi pariwisata untuk membuat agenda pariwisata. Pertama untuk membuat agenda user harus menginputkan nama perjalanan sesuai keinginan user, lalu memilih hotel tempat menginap yang user inginkan, seterusnya user akan menginputkan kapan tanggal akan dimulainya perjalanan, dan user harus memilih kategori pariwisata yang ia inginkan untuk dikunjungi. Lalu sistem akan menampilkan daftar pariwisata yang direkomendasikan untuk user berdasarkan kategori pencarian. Dengan demikian user dapat memilih kembali wisata mana saja yang akan user tambahkan ke dalam daftar agenda perjalanan. 
Jurnal Pseudocode, Volume VI Nomor 1, Februari 2019, ISSN 2355-5920, e-ISSN 2655-1845 www.ejournal.unib.ac.id/index.php/pseudocode

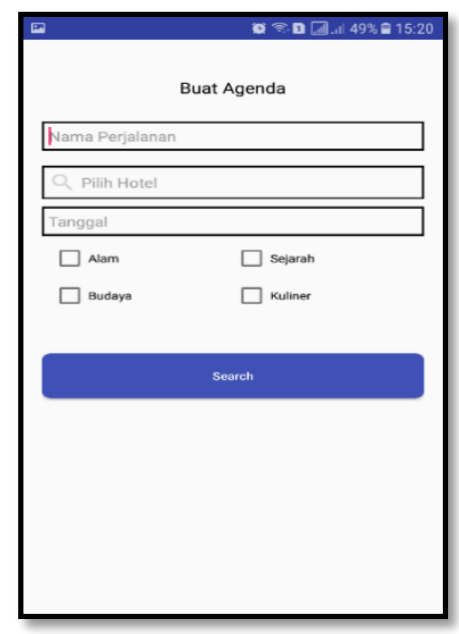

Gambar 5. Antar Muka Pembuatan Agenda Wisata

iv) Halaman Hasil Rekomendasi

merupakan tampilan hasil dari aplikasi setelah user memilih kategori pilihannya maka aplikasi memberian rekomendasi pariwisata berdasarkan kategori yang dipilih, lalu user akan memilih kembali pariwisata yang ingin dikunjungi oleh pengguna untuk disimpan dan akan menjadi sebuah jadwal (agenda) perjalanan pariwisata.

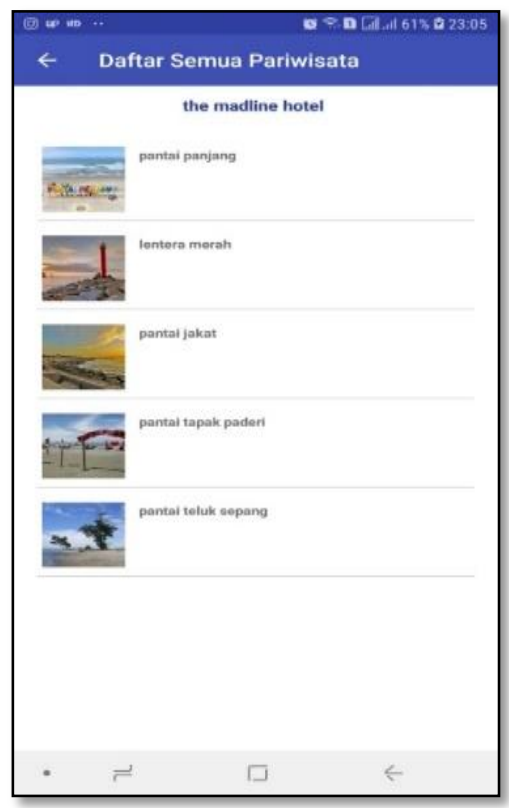

Gambar 6. Antar Muka Hasil Rekomendasi Agenda Wisata

\section{B. Hasil Pengujian}

Pada penelitian ini, terdapat 34 pengujian fungsional antarmuka dari black box testing, berhasil dilakukan. Dengan ini kita dapat mengukur tingkat pengujian fungsional sistem sebagai berikut.

Keberhasilan fungsional $=\frac{34}{34} \times 100 \%=100 \%$

Dengan demikian, uji keberhasilan fungsional sistem mendapatkan hasil pengujian sebesar $100 \%$ berhasil.

Pengujian sistem yang dilakukan pada penelitian ini, dilakukan dengan pengujian kualitas pada sistem yang di bangun. Pengujian kualitas dilakukan dengan menggunakan usability testing.sehingga hasilnya dapat dilihat pada Tabel 1 hasil pengujian dengan menggunakan Usability Testing. Adapun aspek penilai yang menjadi indikator pengujian Usability Testing.

Persentase kesuksesan :
a. $\quad$ Learn $=\frac{4,520}{5} \times 100 \%=90,400 \%$
b. $\quad$ Efficiency $=\frac{4,463}{5} \times 100 \%=89,253 \%$
c. $\quad$ Memory $=\frac{4,465}{5} \times 100 \%=89,293 \%$
d. $\quad$ Error $=\frac{4,808}{5} \times 100 \%=96,160 \%$
e. $\quad$ Satisfied $=\frac{4,433}{5} \times 100 \%=88,653 \%$

Presentasi kesuksesan total $=$ $\sum \frac{\text { Learn }+ \text { Effic }+ \text { Memory }+ \text { Error }+ \text { Satis } f}{5} \times 100 \%=$ $\frac{4,520+4,463+4,465+4,808+4,433}{5} \times 100 \%$
$=90,752 \%$ 
Jurnal Pseudocode, Volume V Nomor 2, September 2018, ISSN 2355-5920, e-ISSN 2655-1845 www.ejournal.unib.ac.id/index.php/pseudocode

Keterangan :

a) Learnability, menjelaskan tingkat kemudahan pengguna atau user untuk menyelesaikan tasktask dasar ketika pertama kali mereka melihat atau berhadapan dengan sistem yang ada.

b) Efficiency, menjelaskan seberapa cepat pengguna dapat menyelesaikan tugas-tugas yang ada saat mereka pertama kali mempelajari sistem tersebut.

c) Memorability, menjelaskan tetang tingkat kemudahan pengguna atau user dalam menggunakan sistem dengan baik, setelah beberapa lama tidak menggunakannya.

d) Errors, menjelaskan kemungkinan terjadinya error atau kesalahan yang dilakukan oleh pengguna dan seberapa mudah mereka dapat mengatasinya.

e) Satisfication, menjelaskan tentang tingkat kepuasan pengguna dalam menggunakan sistem yang telah dibuat
Tabel 1. Hasil Pengunjian Menggunakan Usability Testing

\begin{tabular}{|c|c|c|c|c|c|c|}
\hline \multirow{3}{*}{ No } & \multirow{3}{*}{ Pertanyaan } & \multicolumn{5}{|c|}{ Aspek usibility } \\
\hline & & 1 & 2 & 3 & 4 & 5 \\
\hline & & Learn & Effic & Memory & Error & Satisf \\
\hline \multicolumn{7}{|c|}{ Aspek sistem (system) } \\
\hline 1. & $\begin{array}{lr}\text { Apakah } & \text { simbol-simbol } \\
\text { gambar } & \text { mudah } \\
\text { dipahami? } & \\
\end{array}$ & 4,73 & 4,50 & 4,56 & 0,19 & 4,430 \\
\hline 2. & $\begin{array}{l}\text { Apakah aplikasi jelejah } \\
\text { bengkulu } \\
\text { dioperasikan? }\end{array}$ & 4,60 & 4,46 & 4,44 & 0,14 & 4,380 \\
\hline 3. & $\begin{array}{l}\text { Apakah tampilan warna } \\
\text { pada jelajah bengkulu } \\
\text { enak dilihat dan tidak } \\
\text { membosankan? }\end{array}$ & 4,58 & 4,32 & 4,46 & 0,21 & 4,450 \\
\hline 4. & $\begin{array}{l}\text { Apakah tampilan tulisan } \\
\text { teks pada aplikasi } \\
\text { jelajah bengkulujelas } \\
\text { dan mudah dibaca? }\end{array}$ & 4,53 & 4,43 & 4,41 & 0,15 & 4,40 \\
\hline 5. & $\begin{array}{l}\text { Apakah tampilan pada } \\
\text { jelajah bengkulu mudah } \\
\text { dikenali? }\end{array}$ & 4,53 & 4,54 & 4,48 & 0,15 & 4,48 \\
\hline & Sub Total & 4,59 & 4,45 & 4,47 & 0,17 & 4,43 \\
\hline \multicolumn{7}{|c|}{ Aspek pengguna (user) } \\
\hline 1. & $\begin{array}{l}\text { Apakah tampilan menu } \\
\text { dalam aplikasi jelajah } \\
\text { bengkulu } \\
\text { dikenali? }\end{array}$ & 4,54 & 4,46 & 4,47 & 0,20 & 4,33 \\
\hline 2. & $\begin{array}{l}\text { Apakah menu-menu } \\
\text { yang ada cukup mudah } \\
\text { untuk dipahami? }\end{array}$ & 4,49 & 4,40 & 4,54 & 0,21 & 4,40 \\
\hline 3. & $\begin{array}{lr}\text { Apakah } & \text { tampilan } \\
\text { aplikasi jelajah } \\
\text { bengkulu yang ada } \\
\text { mudah dibaca? }\end{array}$ & 4,45 & 4,59 & 4,42 & 0,23 & 4,32 \\
\hline 4. & $\begin{array}{lr}\text { Apakah } & \text { tampilan } \\
\text { aplikasi } & \text { jelajah } \\
\text { bengkulu menarik? }\end{array}$ & 4,47 & 4,45 & 4,44 & 0,24 & 4,44 \\
\hline 5. & $\begin{array}{l}\text { Apakah tampilan } \\
\text { halaman pada aplikasi } \\
\text { jelajah bengkulu mudah } \\
\text { diingat? }\end{array}$ & 4,60 & 4,57 & 4,48 & 0,26 & 4,47 \\
\hline & Sub Total & 4,51 & 4,49 & 4,47 & 0,23 & 4,39 \\
\hline \multicolumn{7}{|c|}{ Aspek interaksi } \\
\hline 1. & $\begin{array}{l}\text { Apakah mudah mudah } \\
\text { mendapatkan pariwisata } \\
\text { yang di inginkan? }\end{array}$ & 4,52 & 4,46 & 4,37 & 0,21 & 4,46 \\
\hline 2. & $\begin{array}{l}\text { Apakah pariwisata yang } \\
\text { ditawarkan sesuai } \\
\text { dengan kebutuhan? }\end{array}$ & 4,41 & 4,37 & 4,39 & 0,19 & 4,40 \\
\hline 3. & $\begin{array}{lr}\begin{array}{l}\text { Apakah } \\
\text { pariwisata } \\
\text { diakses? }\end{array} & \text { mudah } \\
\end{array}$ & 4,53 & 4,40 & 4,53 & 0,15 & 4,50 \\
\hline 4. & $\begin{array}{l}\text { Apakah menu pada } \\
\text { jelajah bengkulumudah } \\
\text { diingat? }\end{array}$ & 4,41 & 4,54 & 4,44 & 0,15 & 4,43 \\
\hline 5. & $\begin{array}{lr}\text { Apakah } & \text { apakah } \\
\text { mempermudah untuk } \\
\text { melakukan kunjungan } \\
\text { pariwisata Bengkulu? }\end{array}$ & 4,41 & 4,45 & 4,54 & 0,20 & 4,60 \\
\hline \multicolumn{2}{|c|}{ Sub Total } & 4,45 & 4,44 & 4,45 & 0,18 & 4,48 \\
\hline \multicolumn{2}{|c|}{ Total } & 4,52 & 4,46 & 4,46 & 0,19 & 4,43 \\
\hline \multicolumn{2}{|c|}{ Persentase kesuksesan } & $\begin{array}{l}90,4 \\
\%\end{array}$ & $\begin{array}{l}89,25 \\
\%\end{array}$ & $89,29 \%$ & $\begin{array}{l}96,16 \\
\%\end{array}$ & $\begin{array}{l}88,85 \\
\%\end{array}$ \\
\hline
\end{tabular}


Jurnal Pseudocode, Volume VI Nomor 1, Februari 2019, ISSN 2355-5920, e-ISSN 2655-1845 www.ejournal.unib.ac.id/index.php/pseudocode

\section{KESIMPULAN}

Berdasarkan hasil penelitian dan pembahasan mengenai Item Based Collaborative Filtering untuk Rekomendasi Pariwisata Bengkulu Berbasis Android, maka didapatkan kesimpulan sebagai berikut:

1. Penelitian ini telah berhasil membangun aplikasi rekomendasi pariwisata Bengkulu berbasis Android dengan menggunakan metode item based collaborative filtering, sesuai dengan teori yang ada memperoleh hasil pengujian $100 \%$ berhasil pada pengujian dengan menggunakan metode black box, hal ini dinilai dari 41 pengujian fungsional yang dapat dijalankan di aplikasi android.

2. Collaborative filtering untuk rekomendasi pariwisata Bengkulu berbasis Android dapat dibangun dengan tingkat kepuasan user experience sangat baik yaitu sebesar 90,752\% pada pengujian usability testing.

\section{REFERENSI}

[1] Y. H. Putro, "Liputan 6," 29 Agustus 29 Agu 2016. [Online]. Available:

http://regional.liputan6.com/read/2588312/4-aksimenuju-visit-bengkulu-2020.

[2] S. Usman Ependi, "Implementasi Location Based Service Pada Aplikasi Mobile Pencarian Halte BRT Transmusi Palembang," Journal of Information Systems Engineering and Business Intelligence Vol. 2, No. 1, pp. 33-39, 2016.

[3] P. P. Bengkulu, "Pariwisata Provinsi Bengkulu," 2017. [Online]. [Accessed 1 February 2018].

[4] A. Kurniawan, "Sistem Rekomendasi Produk Sepatu Dengan Menggunakan Metode Collaborative Filtering," Seminar Nasional Teknologi Informasi dan Komunikasi 2016 (SENTIKA 2016), pp. 610-614, 2016.

[5] Y. d. Setiawan, "Design Dan Implementasi Sistem Informasi Design Dan Implementasi Sistem Informasi Startup Lokal Bengkulu," 2017.

[6] A. W. A. Bambang Tri Wahyo U, "Sistem Rekomendasi Paket Wisata Se-Malang Raya Menggunakan Metode Hybrid Content Based Dan Collaborative," Vol. 9 No 1, pp. 6-3, 2015.

[7] Y. Setiawan, B. Susilo, A. Erlanshari, S.J. Firdhaus, E. Maryanti, "Design and Implementation of the Culinary Recommendation System Using Sentiment Analysis and Simple Adaptive Weighting in Bengkulu, Indonesia”, 2018, EECSI 2018.

[8] H. Graham, "Arti Kata "agenda" Makna Pengertian dan Definisi," 16 Desember 2016. [Online]. Available: https://artikbbi.com/agenda/.

[9] fidz, "Membuat Sistem Rekomendasi Menggunakan Item-based Collaborative Filtering," www.twoh.co, 2013. [Online]. Available:

https://www.twoh.co/2013/06/04/membuat-sistemrekomendasi-menggunakan-item-based-collaborativefiltering/. [Accessed: 30 Mar-2018], 2013. 